\title{
Influence of age of onset and patient's sex on the prevalence and severity of manifestations of Behçet's syndrome
}

\author{
H. YAZICI, Y. TÜZÜN, H. PAZARLI, S. YURDAKUL, Y. ÖZYAZGAN, \\ H. ÖZDOĞAN, S. SERDAROĞLU, M. ERSANLI, B. Y. ÜLKÜ, AND \\ A. Ü. MÜFTÜOĞLU
}

From the Divisions of Rheumatology and Haematology of the Department of Medicine, and the Departments of Ophthalmology and Dermatology, Cerrahpasa Medical Faculty University of Istanbul, Turkey

SUMMARY Eye disease, arthritis, folliculitis, and thrombophlebitis were more common among males, and erythema nodosum among females, in 297 patients with Behçet's syndrome (BS) at their first visit despite an identical disease duration. Younger males and females (age of onset 24 years or less) had a higher prevalence of eye disease and total clinical activity than did the older patients (age of onset 25 years or more). Among the 51 patients followed up for 52 months (SD 7 months) the total clinical activity became significantly less $(p<0.05)$ in the whole group at the end of this period. This was particularly true for older females. While male sex and a younger age of onset are associated with more severe disease in BS, overall, the syndrome ran an improving or stable course over $4 \frac{1}{2}$ years.

Key words: prognosis, early onset, late onset, sex factors, Behçet's disease, gender.

It has been reported that Behçet's syndrome (BS) runs a more severe course in young men, ${ }^{1}$ but there are no formal data on this aspect of the syndrome. ${ }^{2}{ }^{3}$ We report our experience on the influence of sex and age of onset on the severity of BS in patients attending a multi-disciplinary BS outpatient clinic in Istanbul, Turkey.

\section{Patients and methods}

The referral pattern of the patients and the administration of the clinic have been reported on previously. ${ }^{4}$ All patients fulfilled O'Duffy's criteria ${ }^{5}$ for diagnosis. The onset of the syndrome was defined as the time when the patient fulfilled the diagnostic criteria. Two studies were performed and the same physicians examined the patients throughout the studies:

(A) To determine the influence of the age of onset and the patient's sex on the clinical

Accepted for publication 6 June 1984 .

Correspondence to Dr Hasan Yazıcı, Sefa Sok. 17/4, Şifa-Kadıkoy, Istanbul, Turkey. manifestations of the syndrome by analysing the clinical features at the initial clinical visit of the 297 consecutive patients who had attended since the clinic was started in 1977 (group 1).

(B) To determine the effect of the age of onset and the patient's sex on the prognosis of BS in a subset of group 1. The current clinical state of all patients who had registered at the clinic between June 1977 and May 1979 were compared with their state on initial presentation (group 2). There were 79 patients, of whom 40 had attended the clinic within 12 months of the preparation of the manuscript.

Letters were sent to the remaining 39 patients asking them either to report to the clinic or to return by post a brief questionnaire which inquired about the presence of the major manifestations of the syndrome. Eleven patients reported in person and 11 in writing, six did not return after an initial visit, and 11 were lost to follow-up after a mean follow-up of 8.5 (SD 8.9) months (Table 1).

A clinical activity index was calculated for each 
Table 1 Patients

\begin{tabular}{|c|c|c|c|}
\hline \multirow{2}{*}{\multicolumn{4}{|c|}{$\begin{array}{l}\text { Group 1: patients registered since June } 1977 \\
\text { Group 2: patients registered }\end{array}$}} \\
\hline & & & \\
\hline $\begin{array}{l}\text { June 1977-May } 1979 \\
\text { currently attending }\end{array}$ & 40 & & \\
\hline recalled to clinic & 11 & & \\
\hline replied to questionnaire & 11 & 1 & 79 \\
\hline lost to follow-up & & & \\
\hline after initial visit & 6 & 17 & \\
\hline after follow-up of $8.5 \pm 8.9$ months & 11 & 17 & \\
\hline
\end{tabular}

patient (Table 2). Patients who were 24 years old or younger at the age of onset were classified as the 'early onset' group and those 25 years or older as the 'late onset' group. Improvement or deterioration was judged to have occurred if there had been a change of two points in the clinical activity index and if there had been a change of one point for individual clinical manifestations.

Analyses of variance were used to compare continuous clinical parameters of the early and late onset groups of both sexes in group 1, and paired $t$ tests were used to compare manifestations at initial and last visits in group 2. Data obtained on 11 patients by mail were excluded from these analyses. However, the same data were included when

Table 2 The total clinical activity index (the index for the individual patient is the numerical sum of clinical features)

\begin{tabular}{l}
\hline Eye \\
0 normal \\
1 cells in vitreous and/or anterior chamber only \\
2 vision $50 \%$ \\
3 vision $30 \%$ \\
4 able to see few feet \\
5 blind \\
Skin \\
1 aphthae \\
1 erythema nodosum \\
1 genital ulceration \\
Vascular involvement \\
5 thrombosis of vena cava superior (vcs) and vena cava inferior \\
(vci) and/or arterial occlusion \\
4 thrombosis of $v c s$ or $v c i$ \\
3 calf vein thrombosis (cvt) and/or superficial thrombophlebitis \\
(st) requiring bed rest \\
2 bilateral $c v t$ and/or $s t$ \\
1 unilateral $c v t$ and/or $s t$ \\
Arthritis \\
1 each joint \\
Neurological involvement \\
2 intracranial hypertension \\
4 multiple-sclerosis-/like syndrome \\
5 pyramidal and/or cerebellar involvement \\
\hline
\end{tabular}

Table 3 Age of onset, sex, and disease duration in group 1

\begin{tabular}{|c|c|c|c|c|}
\hline \multirow{2}{*}{$\begin{array}{l}\text { Number of } \\
\text { patients }\end{array}$} & \multirow{2}{*}{$\frac{E M}{64}$} & \multirow{2}{*}{$\frac{E F}{38}$} & \multirow{2}{*}{$\frac{L M}{132}$} & \multirow{2}{*}{$\frac{L F}{63}$} \\
\hline & & & & \\
\hline Age of onset & $21 \cdot 0 \pm 2 \cdot 9^{*}$ & $20 \cdot 6 \pm 3 \cdot 1^{\ddagger}$ & $31 \cdot 7 \pm 6 \cdot 5^{\S}$ & $34 \cdot 5 \pm 6 \cdot 8$ \\
\hline $\begin{array}{l}\text { Age at initial } \\
\text { visit } \\
\text { Disease }\end{array}$ & $24 \cdot 7 \pm 5 \cdot 5$ & $23 \cdot 7 \pm 3 \cdot 8$ & $35 \cdot 8 \pm 7 \cdot 1$ & $37 \cdot 5 \pm 6 \cdot 7$ \\
\hline duration & $3 \cdot 76 \pm 4 \cdot 8$ & $3 \cdot 3 \pm 2 \cdot 9$ & $3 \cdot 6 \pm 3 \cdot 5$ & $2 \cdot 9 \pm 3 \cdot 4$ \\
\hline
\end{tabular}

\footnotetext{
Mean \pm SD.

${ }^{\ddagger} t=0.66$, NS.

$\$ t=2 \cdot 77 ; \mathrm{p}<0 \cdot 001$.

${ }^{+} \mathrm{F}: 0 \cdot 76$, NS.
}

analysing the presence of absence of system involvement during follow-up. $\chi^{2}$ analyses were used for non-parametric data.

\section{Results}

\section{GROUP 1}

The number of patients in each age-sex group, the mean age at the onset of the symptoms and at the initial clinic visit and the duration of disease calculated from those figures are given in Table 3.

All patients were Turkish Caucasians except for one Jew and two Armenians. 273/289 (94\%) had positive pathergy tests and $163 / 226(72 \%)$ were HLA-B5 positive. There were only four patients $(1.3 \%)$ that were pathergy and B5 negative at the same time. ${ }^{6}$ The 'early onset' males (EM) and females $(E F)$ were of similar age $(p<0 \cdot 05)$. The 'late onset' females (LF), on the other hand, were slightly older than 'late onset' males (LM) $(\mathrm{p}<0 \cdot 001)$. Disease duration before presentation at the clinic was similar in all four groups $(p>0.05)$. The total mean disease duration was 4.50 (SD 0.74 ) years.

Table 4 shows the sex ratios for each decade at onset. No patient developed the disease in the first decade. The earliest age of onset was 13 years (two male patients), and the latest 67 years (one male patient). Table 5 depicts the frequency of the main

Table 4 Sex ratios for the decades at onset

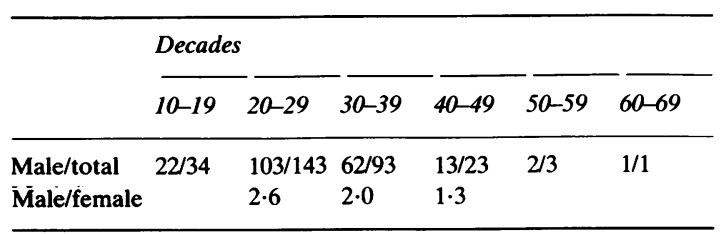




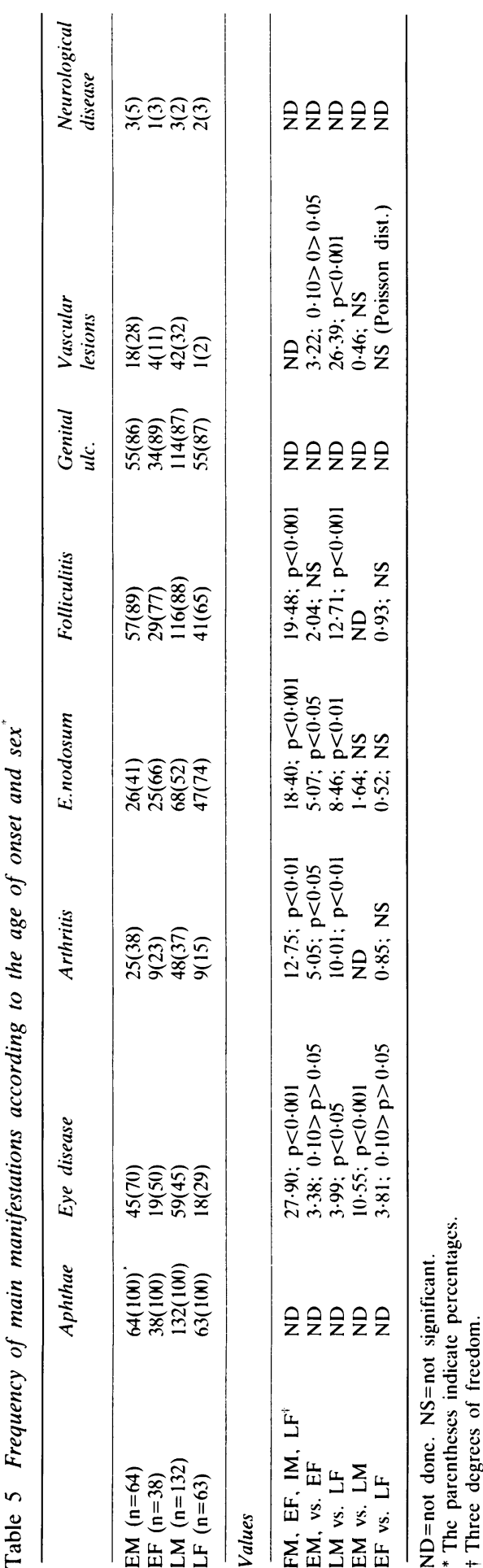

Table 6 Major vascular problems (all male)

\begin{tabular}{llllll}
\hline & \multicolumn{5}{l}{ Decades of onset } \\
\cline { 2 - 5 } & $10-19$ & $20-29$ & $30-39$ & 40 \\
\hline VCI or VCS & 2 & 3 & 3 & - \\
VCI + VCS & - & 1 & - & - \\
Arterial & - & 3 & 1 & - \\
VCI + VCS + arterial & - & 1 & - & -
\end{tabular}

Thrombosis of vena cava inferior (VCI) or vena cava superior (VCS).

manifestations for each age-sex group. The prevalence of oral-aphthae and genital lesions were the same in the four groups. While arthritis and folliculitis were more common among the males of both age groups (for folliculitis this was significant for the 'late onset' group only), erythema nodosum was significantly more common among the females of both groups. There was no difference in the relation of these three lesions to age within the same sex.

The most common serious manifestation of the disease, eye involvement, was more frequent among males than females ('early onset' $0 \cdot 10>p>0 \cdot 05$ : 'late onset $\mathrm{p}<0.05)$ and among 'early onset' than 'late onset' males $(p<0.001)$. There was also a tendency for eye involvement to be more common among the 'early onset' than the 'late onset' females $(0 \cdot 10>p>0 \cdot 05)$. Thirty-six patients had unilateral eye disease (11 EM, $4 \mathrm{EF}, 14 \mathrm{LM}, 7 \mathrm{LF}$ ), without a predilection for any one group $\left(\chi^{2}, \mathrm{df} 3,=2 \cdot 01, \mathrm{NS}\right)$.

Neurological involvement was observed in $9(3 \%)$ patients. In three patients this was benign intracranial hypertension, and one patient each had peripheral neuropathy, brainstem involvement, myelopathy, pyramidal involvement, pyramidal plus cerebellar involvement, and fascial paralysis. No patient had gastrointestinal involvement thought to be due to BS. Thrombophlebitis (superficial and/or calf vein) was more common among the males in both age groups, only one 'late onset' female patient having this manifestation. Age did not seem to influence the prevalence of this complication. Major vascular problems, shown in Table 6 , were seen exclusively among the males mainly in those whose disease had begun in the third and fourth decades.

Table 7 shows the mean total clinical activity (TCA) for each age and sex group. Also shown are the 'pure eye' (PE) activity (those with only eye involvement) and 'clinical activity other than eye' (CAOE) indices. The old females had the least severe TCA and CAOE indices $(p<0.001$, $p<0 \cdot 001)$. Within each age group the males had the more severe TCA index $(\mathrm{p}<0.025$ for 'early' and 
Table 7 Means for total clinical activity, 'pure eye' and 'clinical activity other than eye', indices in group 1

\begin{tabular}{|c|c|c|c|c|}
\hline & $E M$ & $E F$ & $L M$ & $L F$ \\
\hline Total clinical activity & $\begin{array}{l}4 \cdot 96 \pm 3 \cdot 14 \\
(64)\end{array}$ & $\begin{array}{l}3 \cdot 54 \pm 2 \cdot 80 \\
(38)\end{array}$ & $\begin{array}{l}4 \cdot 15 \pm 2 \cdot 94 \\
(132)\end{array}$ & $\begin{array}{l}2 \cdot 41 \pm 2 \cdot 48 \\
(63)\end{array}$ \\
\hline Pure eye activity ${ }^{\dagger}$ & $\begin{array}{l}4 \cdot 62 \pm 2 \cdot 43 \\
(45)\end{array}$ & $\begin{array}{l}4 \cdot 42 \pm 2 \cdot 41 \\
(19)\end{array}$ & $\begin{array}{l}4 \cdot 40 \pm 2 \cdot 80 \\
(59)\end{array}$ & $\begin{array}{l}3 \cdot 72 \pm 2 \cdot 27 \\
(18)\end{array}$ \\
\hline Clinical activity other than eye ${ }^{\dot{p}}$ & $\begin{array}{l}2 \cdot 13 \pm 1 \cdot 68 \\
(64)\end{array}$ & $\begin{array}{l}1 \cdot 73 \pm 1 \cdot 04 \\
(38)\end{array}$ & $\begin{array}{l}2 \cdot 44 \pm 1 \cdot 65 \\
(132)\end{array}$ & $\begin{array}{l}1.45 \pm 1 \cdot 16 \\
(63)\end{array}$ \\
\hline
\end{tabular}

$\mathrm{F}_{(3 \mathrm{df})}=8.87 ; \mathrm{p}<0.001$

EM vs. LM: $t=1 \cdot 77,0 \cdot 10>p>0 \cdot 05$.

${ }^{\dagger} \mathrm{F}_{(3 \mathrm{df})}=1 \cdot 78, \mathrm{NS} ; \quad \begin{aligned} & \ddagger \mathrm{F}_{(3 \mathrm{df})}=6 \cdot 58, \mathrm{p}<0.001 \\ & \\ & { }^{\ddagger} t=1 \cdot 23, \mathrm{~ns} \\ & t=1 \cdot 22, \mathrm{~ns} \\ & t=1 \cdot 32, \mathrm{~ns} \\ & t=4 \cdot 28, \mathrm{p}<0.001\end{aligned}$

EF vs. LF: $t=2 \cdot 12, p<0 \cdot 05$.

EM vs. EF: $t=2 \cdot 30, \mathrm{p}<0.025$.

LM vs. LF: $t=4 \cdot 05, \mathrm{p}<0 \cdot 001$.

Number of cases are shown in parentheses.

p $<0.001$ for 'late'). 'Early onset' males and females had more severe TCA than 'late onset' patients of the same sex. There were no significant differences in PE indices. The CAOE index was significantly lower among 'late onset' females than 'late onset' males.

\section{GROU P 2}

The number of patients in each age-sex group, the mean age of onset of the disease and age at the initial clinic visit, and the calculated disease duration are given in Table 8 . Since there were only three 'early onset' females they were excluded from formal analyses unless specified. There were no significant differences between the remaining three groups in the mean disease durations before patients presented to the clinic and the mean duration of follow-up.

Nine patients received cyclophosphamide or azathioprine, 30 oral and parenteral steroids, 26 colchicine, and 27 levamisole, sometimes concomitantly, in varying doses and for different durations during the follow-up period.

Tables 9 and 10 show the comparison of TCA indices at the last versus the initial visit (by sign test) in the 51 patients examined at the clinic, thus excluding those who answered by mail. There was an overall improvement in the clinical activity $(p<0.05)$. Thus over $4 \frac{1}{2}$ years Behçet's syndrome follows a stable or improving course in most patients. The mean clinical activity indices of the same group of 51 patients (Table 11) shows in particular a significant decrease of indices in the 'late onset' females $(p<0.05)$.

In Table 12 the individual clinical manifestations present at the initial versus the last visits are classified as 'better', 'no change', or 'worse'. It includes data received from 11 patients who answered by mail $(n=62)$. If a clinical manifestation was not present at both the beginning and end of the study it was classified as 'no change'; if one occurred de novo it was counted as 'worse'. The number classified as 'better' exceeded the 'worse' for every clinical finding in all age-sex groups with the exception of eye lesions. Improvement was significant for aphthae and folliculitis for the whole group ( $p<0.05$ and $p<0.01$ respectively), and there was an overall deterioration in eye lesions $(p<0 \cdot 05)$.

Further analysis of eye lesions showed that there were 27 with eye disease among the 51 patients who could be examined at the end of the study period. Of those, three (1 EM and $2 \mathrm{LM})(11 \%)$ had had eye

Table 8 Age of onset, sex, and disease duration in group 2

\begin{tabular}{|c|c|c|c|c|}
\hline & $E M$ & $E F$ & $L M$ & $L F$ \\
\hline & $(n=24)$ & $(N=3)$ & $(n=24)$ & $(n=11)$ \\
\hline Age at initial visit & $21 \cdot 38 \pm 1 \cdot 77^{*}$ & $27,31,21$ & $33 \cdot 37 \pm 5 \cdot 18$ & $36 \cdot 85 \pm 6 \cdot 15$ \\
\hline Age of onset & $20 \cdot 84 \pm 3 \cdot 80$ & $24,23,20$ & $33 \cdot 80 \pm 7 \cdot 57$ & $34 \cdot 33 \pm 6 \cdot 62$ \\
\hline Duration of follow up ${ }^{\dagger}$ (months) & $55 \cdot 46 \pm 9 \cdot 60$ & $43,52,67$ & $52 \cdot 08 \pm 9 \cdot 08$ & $52 \cdot 00 \pm 6 \cdot 72$ \\
\hline
\end{tabular}

Mean $\pm S D .{ }^{\dagger} F_{(3 \text { df })}=1 \cdot 03$, NS. 
Table 9 Clinical activity scores for individual patients

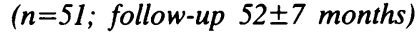

\begin{tabular}{rrllllrlllll}
\hline$E M$ & $(n=19)$ & \multicolumn{1}{ll}{$E F(n=2)$} & \multicolumn{1}{c}{$L M$} & $(n=19)$ & \multicolumn{3}{c}{$L F(n=11)$} \\
\hline $\mathrm{I}$ & $\mathrm{L}$ & $\mathrm{D}$ & $\mathrm{I}$ & $\mathrm{L}$ & $\mathrm{D}$ & \multicolumn{1}{l}{$\mathrm{I}$} & $\mathrm{L}$ & $\mathrm{D}$ & $\mathrm{I}$ & $\mathrm{L}$ & $\mathrm{D}$ \\
10 & 2 & +8 & 3 & 3 & 0 & 4 & 4 & 0 & 8 & 7 & +1 \\
4 & 3 & +1 & 8 & 6 & +2 & 12 & 11 & +1 & 3 & 2 & +1 \\
11 & 9 & +2 & & & & 9 & 11 & -2 & 3 & 0 & +3 \\
10 & 7 & +3 & & & & 4 & 4 & 0 & 4 & 3 & +1 \\
5 & 3 & +2 & & & & 9 & 9 & 0 & 1 & 1 & 0 \\
6 & 9 & -3 & & & & 3 & 7 & -4 & 8 & 5 & +3 \\
3 & 3 & 0 & & & & 10 & 2 & +8 & 5 & 3 & +2 \\
14 & 10 & +4 & & & & 2 & 2 & 0 & 2 & 2 & 0 \\
6 & 7 & -1 & & & & 1 & 4 & -3 & 1 & 0 & +1 \\
6 & 4 & +2 & & & & 3 & 1 & +2 & 2 & 0 & +2 \\
3 & 3 & 0 & & & & 15 & 12 & +3 & 2 & 4 & -2 \\
5 & 1 & +4 & & & & 5 & 2 & +3 & & & \\
7 & 4 & +3 & & & & 6 & 10 & -4 & & & \\
5 & 3 & +2 & & & & 0 & 1 & -1 & & & \\
6 & 5 & +1 & & & & 3 & 1 & +2 & & & \\
9 & 16 & -7 & & & & 2 & 2 & 0 & & & \\
2 & 1 & +1 & & & & 4 & 3 & +1 & & & \\
4 & 4 & 0 & & & & 2 & 1 & +1 & & & \\
4 & 8 & -4 & & & & 3 & 1 & +2 & & & \\
\end{tabular}

$\mathrm{I}=$ Score at initial visit.

$\mathrm{L}=$ Score at last visit.

$\mathrm{D}=$ Difference.

$+=$ Improvement

$-=$ Deterioration

scores of 8-10 (practically blind) at the initial visit compared with seven (3 EM and $4 \mathrm{LM})(25 \%)$ at the final visit. The additional four patients who had become blind had had eye involvement initially. In the whole series only one patient (LF) had de novo eye involvement during the follow-up. Of nine patients with unilateral eye involvement, five ( $3 \mathrm{LM}$ and $2 \mathrm{EM}$ ) became bilateral and 4 (2 LF, $1 \mathrm{EM}$ and 1 LM) remained unilateral during follow-up. Among the 11 patients who answered by mail five had eye disease initially and a further two (1 EM and $1 \mathrm{LM}$ ) developed eye disease later.

There were only two patients with central nervous system involvement. Both had benign intracranial

Table 10 Clinical activity at the last versus initial visit in group 2 ( $n=51$, mean follow-up $=52 \pm 7$ months $)$

\begin{tabular}{lccccc}
\hline & $E M$ & $E F$ & $L M$ & $L F$ & Total $^{*}$ \\
\hline Improved $^{\dagger}$ & 9 & 1 & 6 & 4 & 20 \\
Got worse $^{\dagger}$ & 3 & 0 & 4 & 1 & 8 \\
No change & 7 & 1 & 9 & 6 & 23 \\
Total & 19 & 2 & 19 & 11 & 51 \\
\hline
\end{tabular}

- $\mathrm{p}<0.05$ (sign test).

+ By 2 points (Table 2).
Table 11 Total clinical activity ${ }^{*}$ at the first and last visit in group 2

\begin{tabular}{lllll}
\hline & $\begin{array}{l}E M \\
(n=19)\end{array}$ & $\begin{array}{l}E F \\
(N=2)\end{array}$ & $\begin{array}{l}L M \\
(n=19)\end{array}$ & $\begin{array}{l}L F \\
(n=11)\end{array}$ \\
\hline First visit & $6 \cdot 32 \pm 3 \cdot 14$ & 3,3 & $5 \cdot 10 \pm 4 \cdot 04$ & $3 \cdot 54 \pm 2 \cdot 50$ \\
Last visit & $5 \cdot 37 \pm 3 \cdot 89^{\ddagger}$ & & $4 \cdot 63 \pm 3 \cdot 99^{\ddagger}$ & $2 \cdot 45 \pm 2 \cdot 25^{\S}$ \\
\hline
\end{tabular}

Mean \pm SD.

${ }^{\dagger} t=1 \cdot 23$, NS.

${ }^{\ddagger} t=0.75$, NS.

${ }_{t} t=2 \cdot 53, \mathrm{p}<0 \cdot 05$.

hypertension which improved. One patient (an EM) developed ulcerative colitis and had to have emergency surgery during follow-up and is currently asymptomatic.

There were no deaths among the 62 patients about whom information is available.

Table 12 Comparison of clinical findings at the last visit (or by mail) versus the initial visit in group $2(n=62)$

\begin{tabular}{|c|c|c|c|c|c|c|c|}
\hline & $N$ & $\begin{array}{l}E M \\
24\end{array}$ & $\begin{array}{l}E F \\
3\end{array}$ & $\begin{array}{l}L M \\
24\end{array}$ & $\begin{array}{l}L F \\
11\end{array}$ & $\begin{array}{l}\text { Total } \\
62\end{array}$ & Significance ${ }^{*}$ \\
\hline Aphthae & $\begin{array}{l}\text { B } \\
\mathbf{N} \\
\mathbf{W}\end{array}$ & $\begin{array}{r}9 \\
11 \\
4\end{array}$ & $\begin{array}{l}2 \\
1 \\
0\end{array}$ & $\begin{array}{r}7 \\
15 \\
2\end{array}$ & $\begin{array}{l}2 \\
8 \\
1\end{array}$ & $\begin{array}{r}20 \\
35 \\
7\end{array}$ & $\mathrm{p}<0.05$ \\
\hline Eye lesions & $\begin{array}{l}\text { B } \\
\mathbf{N} \\
\mathbf{W}\end{array}$ & $\begin{array}{r}5 \\
9 \\
10\end{array}$ & $\begin{array}{l}1 \\
2 \\
0\end{array}$ & $\begin{array}{r}1 \\
18 \\
5\end{array}$ & $\begin{array}{l}0 \\
7 \\
4\end{array}$ & $\begin{array}{r}7 \\
36 \\
19\end{array}$ & $\mathrm{p}<0.05$ \\
\hline Arthritis & $\begin{array}{l}\text { B } \\
\mathbf{N} \\
\mathbf{W}\end{array}$ & $\begin{array}{r}3 \\
21 \\
0\end{array}$ & $\begin{array}{l}0 \\
3 \\
0\end{array}$ & $\begin{array}{r}3 \\
20 \\
1\end{array}$ & $\begin{array}{r}1 \\
10 \\
0\end{array}$ & $\begin{array}{r}7 \\
54 \\
1\end{array}$ & NS \\
\hline E. nodosum & $\begin{array}{l}\mathbf{B} \\
\mathbf{N} \\
\mathbf{W}\end{array}$ & $\begin{array}{r}3 \\
19 \\
2\end{array}$ & $\begin{array}{l}2 \\
1 \\
0\end{array}$ & $\begin{array}{r}3 \\
17 \\
4\end{array}$ & $\begin{array}{l}5 \\
5 \\
1\end{array}$ & $\begin{array}{r}13 \\
42 \\
7\end{array}$ & NS \\
\hline Folliculitis & $\begin{array}{l}\text { B } \\
\mathbf{N} \\
\mathbf{W}\end{array}$ & $\begin{array}{r}8 \\
11 \\
5\end{array}$ & $\begin{array}{l}2 \\
1 \\
0\end{array}$ & $\begin{array}{r}12 \\
12 \\
0\end{array}$ & $\begin{array}{l}4 \\
7 \\
0\end{array}$ & $\begin{array}{r}26 \\
31 \\
5\end{array}$ & $\mathrm{p}<0.01$ \\
\hline Genital lesions & $\begin{array}{l}\text { B } \\
\mathbf{N} \\
\mathbf{W}\end{array}$ & $\begin{array}{r}10 \\
9 \\
5\end{array}$ & $\begin{array}{l}1 \\
1 \\
1\end{array}$ & $\begin{array}{r}8 \\
13 \\
3\end{array}$ & $\begin{array}{l}3 \\
8 \\
0\end{array}$ & $\begin{array}{r}22 \\
31 \\
9\end{array}$ & NS \\
\hline Vascular lesions & $\begin{array}{l}\mathbf{B} \\
\mathbf{N} \\
\mathbf{W}\end{array}$ & $\begin{array}{r}4 \\
18 \\
2\end{array}$ & $\begin{array}{l}0 \\
3 \\
0\end{array}$ & $\begin{array}{r}8 \\
13 \\
3\end{array}$ & $\begin{array}{r}0 \\
11 \\
0\end{array}$ & $\begin{array}{r}12 \\
45 \\
5\end{array}$ & NS \\
\hline $\begin{array}{l}\text { Neurological } \\
\text { lesions }\end{array}$ & $\begin{array}{l}\mathbf{B} \\
\mathbf{N} \\
\mathbf{W}\end{array}$ & $\begin{array}{r}2 \\
22 \\
0\end{array}$ & $\begin{array}{l}0 \\
3 \\
0\end{array}$ & $\begin{array}{r}0 \\
24 \\
0\end{array}$ & $\begin{array}{r}0 \\
11 \\
0\end{array}$ & $\begin{array}{r}2 \\
58 \\
0\end{array}$ & NS \\
\hline
\end{tabular}

Sign test.

$\mathrm{N}=$ no change.

$\mathrm{B}=$ better.

$\mathbf{W}=$ worse . 


\section{Discussion}

In group 1 the disease duration before presentation to the clinic was determined from the patient's history. Nevertheless, the similarity of disease duration between the four groups (Table 3) made comparisons of severity valid. Also the similarity of the mean ages of both sexes in the early and late onset groups (Table 3 ) permitted analysis of the influence of sex on disease presentation independently of age.

Among major clinical manifestations arthritis and folliculitis were more common in the late onset male group and erythema nodosum, as previously reported $^{7}$ in the females (Table 5). However, none of these three lesions seemed to be age dependent. Erythema nodosum was the only manifestation of BS that was more common in females (Table 5). It is to be noted that eyrthema nodosum due to other conditions is also more frequent among women. ${ }^{8}$

Eye disease was more common among the males (Table 5), as previously noted. ${ }^{1}$ However, among those with eye disease its severity did not seem to differ between the age-sex subsets (Table 7). The CAOE index, on the other hand, was greater for late onset and not for early onset males as compared with the females (Table 7).

We interpret these findings as suggesting that eye involvement is the chief indicator of disease severity in those with early onset. In the older patients, in whom the prevalence of eye involvement is significantly less in both sexes (Table 5), other features of the syndrome (for example, thrombophlebitis) cause more severe disease, again in males. Table 7 also shows that, in addition to the higher prevalence of eye involvement among those with early onset, the mean indices for TCA are also significantly greater when compared with the older patients of either sex. This further suggests that the age of onset and the patient's sex contribute separately to the severity of BS. We are unaware of other formal studies on this issue.

Thrombophlebitis was more common in men (Table 5), and all major vascular complications (10/14 of which involved venae cavae) occurred only in males (Table 6). Thrombophlebitis did not show any trend with age (Table 5). However, major vascular complications showed a tendency to occur in patients with a younger age of onset. The fact that the young male usually has the most severe form of vascular involvement has also been reported previously. ${ }^{1}$ In view of the well established association of thrombophlebitis with oestrogens, ${ }^{9}$ its striking prevalence in men with BS remains unexplained.

The syndrome very rarely developed before puberty or after the age of 50 (Table 4), as others have found. ${ }^{10}$ When this is coupled with male predominance in each decade of onset, and the more severe course in the male, one is forced to speculate on the possible influence of sex hormones on disease expression. Such studies are lacking.

The cohort study (group 2) achieved a completion rate of $62 / 79(78 \%)$. O'Duffy first reported on the prognosis of BS in 1979. ${ }^{11} \mathrm{He}$ followed up 37 patients for a mean of 4.5 years, which was identical to our mean follow-up of 54 months. The sex ratio (12 men/25 women) in his series was different from ours and he did not attempt to relate prognosis to sex and the age of onset. His overall interpretation was that Behçet's disease had a guarded prognosis, with a quarter of the patients dying or becoming blind by the end of five years. There were six deaths in O'Duffy's series but none in ours. Only $4 / 24$ $(17 \%)$ of our patients with eye disease progressed to blindness, and only one additional patient developed eye disease de novo during follow-up. This figure excludes five patients who progressed from unilateral to bilateral eye involvement, which is in keeping with our previous observation that eye involvement is infrequently a late manifestation once diagnostic criteria are met, ${ }^{12}$ at least for Turkish patients. Since the number of females with eye involvement in group 2 is small, one cannot analyse the effect of sex on the visual prognosis with certainty. However, all seven patients who became blind were males. There is a suggestion that younger males might have a tendency to progressive deterioration of eye lesions (Table 12).

Apart from eye involvement every other manifestation tended to get better with time, and overall the late onset females had the best prognosis (Tables 10 and 11). This might be anticipated from the findings in group 1 , in which they had the least disease activity at presentation. The fact that the severity of the syndrome abates with time has also been stated by others. ${ }^{1}$

In summary, the age of onset and the patient's sex markedly influence disease expression in BS. Male sex and a younger age of onset seem to contribute separately to more severe disease. In another syndrome of vasculitis, SLE, the clinical observations of the effects of sex and age differences on disease activity produced major advances in the understanding of that entity. ${ }^{13}$ The same might be expected in BS.

The authors thank Dr Colin G. Barnes for his help in preparation and critique of the manuscript. The help of Ms Şake Cangözayan, Berrin Yazıci, and Emine Evcimen is also acknowledged. This work was partly supported by the Turkish Scientific and Research Council (TUBITAK), project No TAG 484. 


\section{References}

1 Shimizu T. Ehrlick G E, Inaba G, Kozabura H. Behçet's disease (Behçet's syndrome). Semin Arthritis Rheum 1979; 8: 223-60.

2 Dilşen N, Koniçe M, Övül C. Behçet's disease. Excerpta Medica International Congress Series 467. Amsterdam: Excepta Medica, 1979.

3 Inaha G, ed. Behçet's disease Pathogenetic mechanisms and clinical features. Tokyo: Japan Medical Research Foundation Publication No. 18, 1982.

4 Yurdakul S. Yazıcı H, Tüzün Y, et al. The arthritis of Behçet's disease: a prospective study. Ann Rheum Dis 1983; 42: 505-15.

5 O'Duffy J D. Suggested criteria for diagnosis of Behçet's disease. Abstracts. 6th Pan American Congress on Rheumatic Disease, p. 18 Toronto: Canada, 1974: 18.

6 Yazıcı H, Tüzün Y, Pazarlı H, Yalçın B, Yurdakul S Müftüoğlu A. The combined use of HLA-B5 and the pathergy test as diagnostic markers of Behçet's disease in Turkey. $J$ Rheumatol 1980; 7: 206-10.

7 Müftüoğlu A Ü, Yazıcı H, Yurdakul S, et al. Behçet's disease: lack of correlation of clinical manifestations with HLA antigens. Tissue Antigens 1981; 17: 226-30.

8 Johnson M L. Erythema nodosum. In: Wyngaarden J B, Smith L H, eds. Cecil's textbook of medicine. Philadelphia: Saunders, 1982: 2280.

9 Owen C A, Walter Bowie E J. Predisposing factors in thrombosis. In: Kwaan H C. Walter Bowie E J, eds. Thrombosis. Philadelphia: Saunders, 1982: 29-56.

10 Shimizu T. Clinicopathological studies on Behçet's disease. In Dilşen N, Koniçe M, Övül C, eds. Behçet's disease. Excerpta Medica International Congress Series 467. Amsterdam: Excerpta Medica, 1979: 9-43.

11 O'Duffy J D. Prognosis in Behçet's syndrome. In: Dilşen N, Koniçe M, Övül C, eds. Behçet's disease. Excerpta Medica International Congress Series 467. Amsterdam: Excerpta Medica, 1979: 191-196.

12 Yazıcı $\mathrm{H}$, Tüzün $\mathrm{Y}$, Pazarlı $\mathrm{H}$, Yurdakul S, Yalçın B Müftüoğlu A. Behçet's disease as seen in Turkey. Haematologica 1980: 65: 381-3.

13 Talal N. Introduction to Proceedings of the Knoc Foundation Conference on Sex Factors, Steroid Hormones and the Host Response. Arthritis Rheum 1977; 22: vi-vii. 